\title{
Endoscopic approach to anastomotic leaks: partially covered self-expandable stents. A single center's experience
}

\author{
Ulaş Aday, Mustafa Duman, Kamuran Cumhur Deđer, Hüseyin Çiyiltepe, Ebubekir Gündeş, \\ Durmuş Ali Çetin, Cebrail Akyüz, Orhan Uzun
}

Department of Gastroenterological Surgery, Kartal Kosuyolu High Speciality Education and Training Hospital, Istanbul, Turkey

Submitted: 11 January 2017

Accepted: 7 February

Arch Med Sci Civil Dis 2017; 2: e29-e34

DOI: https://doi.org/10.5114/amscd.2017.66390

Copyright $\odot 2017$ Termedia \& Banach

\section{Abstract}

Introduction: Anastomotic leakage is an important and undesirable major complication after upper and lower gastrointestinal surgery. This complication can lead to significant morbidity and mortality and prolonged hospital stay. The objective of this study was to evaluate the safety and technical and clinical outcomes of temporary partially covered self-expandable metallic stent (PCSEMS) placement for treating anastomotic leaks after gastrointestinal tract surgery.

Material and methods: Medical records of 9 patients who had undergone partial covered self-expandable esophageal or colonic stenting either for colorectal anastomotic leak or esophageal anastomotic leak in Kartal Kosuyolu Higher Specialty Training and Research Hospital between April 2012 and October 2015 were collected. Living patients were recalled for the policlinic follow-up and recent status was recorded.

Results: The mean age was 57 (37-78) years. Six of the patients were male and 3 of them female. Stents were successfully placed in all patients in the fistula localization on the first attempt. Stent migration was encountered in 3 patients and restenting was performed in 2 of these patients. No complications were seen related to the indwelling stents. Stent treatment failure occurred in 2 of the 9 patients. The mean removal time of the stent was $43(5-70)$ days and it was not possible to get the stent out in 1 patient.

Conclusions: Endoscopic stenting is a minimally invasive and highly effective procedure that gives promise for the treatment of fistula after digestive surgery in the future.

Key words: anastomotic leak, endoscopy, fistula, stent.

\section{Introduction}

It is important to point out that the anastomosis complications that occur after gastrointestinal surgery are crucial. An anastomotic leakage is a serious complication that can arise after upper and lower gastrointestinal surgery $[1,2]$. This complication can lead to significant morbidity and mortality and prolonged hospital stay. The reported incidence of lower gastrointestinal anastomosis leaks ranges from $1 \%$ to $30 \%$ [3, 4]. Despite advances in surgical techniques, anastomotic leakage after left colon surgery continues to occur at a high rate [1]. Anastomotic leakages also cause

\author{
Corresponding author: \\ Ulaş Aday \\ Department of \\ Gastroenterological Surgery \\ Kartal Kosuyolu \\ High Speciality \\ Education and \\ Training Hospital \\ 34685 Istanbul, Turkey \\ Phone: +90 5302933895 \\ E-mail: ulasaday@gmail.com
}


high mortality and morbidity after upper gastrointestinal surgery. Particularly after an esophagectomy, anastomotic leakage occurs at a rate of $4-30 \%$ and has a high mortality rate $[2,5,6]$.

Until recently, the approach for managing postoperative anastomotic leaks was mainly surgical or radiological percutaneous drainage, as well as antibiotic therapy, bowel rest, parenteral nutrition and, if necessary, diversion [1, 2, 5-7].

In recent years, self-expandable stents, which were already used for the palliative treatment modality of malign obstructions in the gastrointestinal tract, began to be used for treatment of gastrointestinal anastomosis leakages [5-8]. Today, endoscopic self-expanded covered stent placement is well accepted as an effective treatment modality for anastomotic leakage in the gastrointestinal tract, and its usage is gradually increasing [2, 5-8].

The aim of this study was to evaluate the safety and technical and clinical outcomes of placing temporary partially covered self-expandable metallic stents (PCSEMS) to treat anastomotic leaks after gastrointestinal tract surgery.

\section{Material and methods}

In this retrospective study, medical records were reviewed for 9 patients who had undergone partial covered self-expandable esophageal or colonic stenting either for colorectal anastomotic leak or esophageal anastomotic leak in Kartal Kosuyolu Higher Specialty Training and Research Hospital, Gastroenterological Surgery Department, between April 2012 and October 2015. This study was approved by the institutional review board of Kartal Dr. Lütfi Kırdar Education and Research Hospital (prot: 89513307/1009/517). The details of the endoscopic procedures were explained to the patients and informed consent was obtained. When the retrospective study was completed, living patients were recalled for the policlinic follow-up and their recent status was recorded.

Demographic properties of patients, primary diagnosis, surgical method, preoperative chemoradiotherapy delivery status, fistula localization, stenting time, duration of stenting, complications related to stenting and clinical results were recorded. Surgical and endoscopic procedures were identified in which treatment failure and longterm follow-up complications had occurred with stenting.

Fistula was defined as: intestinal drainage from thoracic or abdominal drains following upper gastrointestinal surgery; detection of fistula tract or fluid collection on oral-intravenous contrasted computed tomography (CT); intestinal drainage from drain, incision of vagina upon lower gastrointestinal surgery; detection of fistula tract or fluid collection on rectal-intravenous contrasted CT. Mid- azolam and/or fentanyl sedation was applied to all patients by the anesthesiology team while under endoscopic stenting. Intervention was done under direct vision and fluoroscopy was not needed.

Success was determined by completion of leakage clinically and regression of collections radiologically. Failure of the treatment was defined as inability to place the stent or surgical attempt due to the ongoing fistula despite the stent placement. The patients for whom the stenting was successful underwent endoscopic evaluation twice a month for the first month and then were evaluated when the stent was taken out.

\section{Statistical analysis}

Statistical Package for the Social Sciences (SPSS 21 Inc., Chicago, IL, USA) was used for biostatistical analyses. The data collected were expressed as mean (minimum - maximum) or in percentages.

\section{Results}

The mean age was 57 (37-78) years. Six of the patients were male and 3 of them female. All had undergone a stenting procedure due to postoperative fistula. The diagnosis of the patients were as follows: 3 patients rectum cancer; 1 patient gastric cancer; 1 patient pseudomyxoma peritonei; 1 patient distal esophagus squamous cell cancer; and 1 patient caecum cancer which originated from attenuated familial adenomatous polyposis (AFAP). The remaining 2 patients were operated on for benign conditions: 1 had symptomatic esophagus diverticula and the other suffered from jejunal perforation related to bevacizumab therapy. We performed defunctioning stoma on 2 of the 5 patients who had undergone a colorectal resection procedure. The clinical and demographical properties of the patients are shown in Table I.

The operation procedures were performed as follows: 3 patients underwent low anterior resection for rectum cancer; 1 patient underwent a total abdominal colectomy + iliorectal anastomosis procedure for caecum carcinoma derived from AFAP; cytoreductive surgery + hyperthermic intraperitoneal chemotherapy (CRS + HIPEC) was performed on 1 patient who had a diagnosis of pseudomyxoma peritonei; one primary suture repair and jejunal patch plasty was performed due to afferent intestinal loop perforation in a patient who had undergone right hemicolectomy and antrectomy + Bilroth II gastrojejunostomy for advanced colon cancer 10 months before perforation and was under bevacizumab therapy. The procedure was unsuccessful and the stent was placed for the fistula that had developed after multiple relaparotomy sessions.

Stents were successfully placed in all patients in the fistula localization on the first attempt. The 
Table I. Clinical and demographic properties of patients

\begin{tabular}{|c|c|c|c|c|c|c|}
\hline $\begin{array}{l}\text { Patient } \\
\text { no. }\end{array}$ & Age & Gender & Diagnosis & $\begin{array}{c}\text { Neoadjuvant } \\
\text { CRT }\end{array}$ & Surgical procedure & $\begin{array}{c}\text { Defunctioning } \\
\text { stoma }\end{array}$ \\
\hline 1 & 37 & M & $\begin{array}{c}\text { Attenuated FAP + } \\
\text { caecal cancer }\end{array}$ & No & Total colectomy + IRA & No \\
\hline 2 & 34 & M & Distal esophagus SCC & Yes & Ivor-Lewis esophagectomy & \\
\hline 3 & 66 & M & Rectal cancer & Yes & LAR & Yes \\
\hline 4 & 65 & $\mathrm{~F}$ & Rectal cancer & No & LAR & No \\
\hline 5 & 58 & M & $\begin{array}{c}\text { Pseudomyxoma } \\
\text { peritonei }\end{array}$ & No & $\begin{array}{c}\text { Subtotal colectomy } \\
+ \text { cytoreductive surgery } \\
+ \text { HIPEC + ileosigmoidal } \\
\text { anastomosis }\end{array}$ & No \\
\hline 6 & 76 & $\mathrm{~F}$ & Gastric cancer & No & $\mathrm{TG}+\mathrm{EJ}$ & \\
\hline 7 & 52 & M & Esophagus diverticula & & Diverticulectomy & \\
\hline 8 & 44 & M & $\begin{array}{l}\text { Proximal jejunal } \\
\text { perforation }\end{array}$ & & Primary repair & \\
\hline 9 & 78 & $\mathrm{~F}$ & Rectal cancer & No & LAR & Yes \\
\hline
\end{tabular}

mean stenting time was 18 postoperative days (6-53). Stent migration was encountered in 3 patients (patients 2, 7 and 8) and restenting was performed on 2 of these patients. No complications were observed related to the indwelling stents (Table II). Stent treatment failure occurred in 2 of the 9 patients. Anastomotic leakage was continued despite the proper placement of the stent in 1 patient (no. 5) leading to stoma creation with anastomotic region resection eventually. Stent migration was the reason for ongoing leakage in the other patient (no. 8); he finally underwent surgery for the fistula. The mean removal time of the stent was 43 (5-70) days, and it was not possible to get the stent out in 1 patient (no. 3).

The mean follow-up time of living patients was 29 (18-45) months. Two patients underwent endoscopic dilatation due to stenosis. Peritoneal and liver metastases occurred in 1 patient (no. 3). His chemotherapy is still ongoing and stent removal and ostomy closure was impossible for him. No recurrence was seen in 5 of the remaining patients. Two patients died because of multiorgan failure related to fistula-associated sepsis. One of these patients (no. 9) was clinically unresponsive although the fistula was controlled by the in-

Table II. Stent application and clinical outcomes

\begin{tabular}{|c|c|c|c|c|c|c|c|}
\hline $\begin{array}{l}\text { Patient } \\
\text { no. }\end{array}$ & $\begin{array}{l}\text { Stent } \\
\text { insertion } \\
\text { time } \\
\text { [PO day] }\end{array}$ & $\begin{array}{c}\text { Stent } \\
\text { removal } \\
\text { time } \\
\text { [day] }\end{array}$ & $\begin{array}{l}\text { Localization } \\
\text { of anastomosis }\end{array}$ & $\begin{array}{c}\text { Stent } \\
\text { migration }\end{array}$ & Restenting & Success & Complication \\
\hline 1 & 21 & 62 & Ileorectal & No & No & Yes & No \\
\hline 2 & 14 & 45 & Esophagogastric & Yes & Yes & Yes & No \\
\hline 3 & 53 & $\begin{array}{l}\text { Could } \\
\text { not be } \\
\text { removed }\end{array}$ & Colorectal & No & No & Yes & No \\
\hline 4 & 10 & 70 & Colorectal & No & No & Yes & No \\
\hline 5 & 11 & 5 & Ileosigmoid & No & No & No & No \\
\hline 6 & 17 & 29 & Esophagojejunostomy & No & No & Yes & No \\
\hline 7 & 6 & 72 & Esophagus & Yes & Yes & Yes & No \\
\hline 8 & 15 & 11 & Jejunum & Yes & No & No & No \\
\hline 9 & 16 & 51 & Colorectal & No & No & Yes & No \\
\hline
\end{tabular}

PO - post-operative 
Table III. Long-term follow-up outcomes

\begin{tabular}{|lcccc|}
\hline Patient no. & Stenosis & Follow-up time [months] & Patient status & Additional application \\
\hline 1 & - & 43 & Alive & \\
\hline 2 & + & 24 & Alive & Dilatation \\
\hline 3 & - & 27 & Alive & \\
\hline 4 & - & 24 & Alive & Dilatation \\
\hline 5 & - & 20 & Alive & \\
\hline 6 & - & 18 & Alive & \\
\hline 7 & + & 45 & Alive & \\
\hline 8 & & 0 & Death & \\
\hline 9 & & 0 & Death & \\
\hline
\end{tabular}

dwelling stent. Long-term follow-up outcomes are shown in Table III.

\section{Discussion}

Stent usage has become more popular in the era of endoscopic innovations for complications in gastrointestinal surgery such as anastomotic leakage, fistula and stenosis $[8,9]$. Stent implantation through the fistula location avoids fluid collection and prevents infection by formation of a barrier between the defect and the intraluminal space [10].

Surgeons encounter a variety of life-threatening complications after upper gastrointestinal surgical procedures. Anastomotic leakage ratios are $3-25 \%$ for esophageal surgery and $5-8 \%$ for gastric surgery $[11,12]$. The mortality rate is extremely high for redoing gastrointestinal surgery. For this reason self-expandable metallic stent utilization receives more attention every day. It has been reported that the endoscopic stent success rate is $40-80 \%$ [11-13].

Stent migration stands out in the context of treatment failure. To prevent this event, clip application, large size of indwelling stent, suture fixation and partial covered stent usage have been shown to decrease the treatment failure rates [2, $14,15]$.

The PCSEMS was reapplied to 4 of the 9 patients (nos. 2, 6, 7 and 8) due to the developed fistula after various upper digestive tract operations. Stent migration occurred in 3 patients. In 2 of these patients (nos. 2 and 7), fistulas were controlled after inserting larger stents. Stent migration developed in the other patient (no. 8) with an afferent jejunal loop fistula. Although the leak was controlled for the first week after the first stenting attempt, the patient died because of sepsis related to stent migration.

According to the current literature, the suggested stent removal time is $2-8$ weeks $[2,12,14,15]$.
Postponing of stent removal is associated with ulcer formation, stricture, perforation and bleeding. There are conflicting reports on the length of removal time among different kinds of stents. Van Heel et al. [16] reported that complications and failure rates are higher when the removal time is longer.

Two stenoses developed in 2 of the 9 patients (nos. 2 and 7), for whom endoscopic dilatation was needed. The patients symptoms were relieved after repeating dilatation applications. Stent length of stay time was long in these patients ( 45 and 72 days), and this was probably related to the developed stenosis.

Anastomosis leakage following colorectal surgery is a significant cause of high levels of morbidity and mortality. Conventional approaches involve antibiotics, bowel rest, percutaneous drainage of collections and surgical drainage with stoma creation in the context of excessive peritoneal contamination [17]. An increasing number of reports indicate the efficacy of self-expandable metallic stents in the treatment of malign and benign obstructive colorectal diseases and postoperative fistulas [18-21]. DiMaio et al. [10] concluded after their small case series that they had an $80 \%$ stenting success rate following lower digestive tract surgery. Fistulas which develop after cancer surgery are associated with a low quality of life and increasing hospital stay and cost [18]. Lamazza et al. [22] reported that they had successfully treated 8 of 10 fistula patients after colorectal surgery.

Chi et al. [23] also claimed that they had achieved healing of colorectal anastomosis fistula in 10 of 12 patients with covered self-expandable stents. Anal pain and migration related to the stent were a significant problem and were frequently encountered when the anastomosis was within $5 \mathrm{~cm}$ of the anal canal. Partially covered stents have proximal and distal mesh flares for 
tissue in growth to prevent stent migration and create an effective seal [14]. On the other hand, this feature may result in impaction of the stent to the tissue wall by excessive fibrosis and granulation tissue leading to perforation or inability to remove the stent $[24,25]$. In the case of stent removal difficulty, the 'stent-in-stent' procedure can be used to prevent complications [25].

In this study, 5 patients underwent a PCSEMS procedure to treat a lower gastrointestinal surgery leak after surgery. No documented anal pain or migration were seen in the patients. Four of the 5 (80\%) patients were treated with stent placement. Failure occurred in 1 patient who had an ongoing leakage from the ileosigmoidal anastomosis despite the stent placement. This patient underwent a surgical procedure by resection of the anastomotic region and creation of a stoma. In one of our patients (no. 3), the stent could not be removed because of the dense fibrosis and granulation, even though the leakage was healed. Peritoneal dissemination and liver metastases developed in the 27-month follow-up and no complication was seen related to the stent. Limitations of our study are the small sample size, retrospective study, the patients being non-homogeneous according to the etiologies, anatomic localizations and lack of a control group.

In conclusion, the treatment of life-threatening fistulas following gastrointestinal surgery with redo surgery has high morbidity and mortality rates. Endoscopic stenting is a minimally invasive and highly effective procedure that holds promise in the future treatment of fistulas after gastrointestinal system surgery. New and different kinds of stents are required because of observed complications such as stent migration, stenosis following stent removal and difficulty in taking out the stent, particularly for partially covered stents.

\section{Conflict of interest}

The authors declare no conflict of interest.

\section{References}

1. Cooper CJ, Morales A, Othman MO. Outcomes of the use of fully covered esophageal self-expandable stent in the management of colorectal anastomotic strictures and leaks. Diagn Ther Endosc 2014; 2014: 187541.

2. Leenders BJM, Stronkhorts A, Smulders FJ, Nieuwenhuijzen GA, Gilissen LPL. Removable and repositionable covered metal self-expandable stents for leaks after upper gastrointestinal surgery: experiences in a tertiary hospital. Surg Endosc 2013; 27: 2751-9.

3. Hirst NA, Tiernan JP, Millner PA, Jayne DG. Systematic review of methods to predict and detect anastomotic leakage in colorectal surgery. Colorectal Dis 2013; 16: 95-109.

4. Bertelsen CA, Andreasen AH, Jorgansen T, Harling $\mathrm{H}$. Anastomotic leakage after anterior resection for rectal cancer: risk factors. Colorectal Dis 2010; 12: 37-43.
5. Al-issa MA, Petersen TI, Taha AY, Shehatha JS. The role of esophageal stent placement in the management of postosephagectomy anatomotic leak. Saudi J Gastroenterol 2014; 20: 39-42.

6. Kauer WKH, Stein HJ, Dittler HJ, Siewert JR. Stent implantation as a treatment option in patients with thoracic anastomotic leaks after esophagectomy. Surg Endosc 2008; 22: 50-3.

7. Schweigert M, Dbecz A, Stadlhuber RJ, Muschweck H, Stein HJ. Treatment of intrathoracic esophageal anastomotic leaks by means of endoscopic stent implantation. Interact Cardiovasc Thorac Surg 2011; 12: 147-51.

8. Bonin EA, Baron TH. Update on the indications and use of colonic stents. Curr Gastroenterol Rep 2010; 12: 374-82.

9. Salminen P, Gullichsen R, Laine S. Use of self-expandable stents for the treatment of esophageal perforations and anastomotic leaks. Surg Endosc 2009; 23: 1526-30.

10. DiMaio CJ, Dorfman MP, Gardner GJ, et al. Covered esophageal self-expandable metal stents in the nonoperative management of postoperative colorectal anastomotic leaks. Gastrointest Endosc 2012; 76: 431-5.

11. Hoeppner J, Kulemann B, Seifert G, et al. Covered self-expanding stent treatment for anastomotic leakage: outcomes in esophagogastric and esophagojejunal anastomoses. Surg Endosc 2014; 28: 1703-11.

12. Dray X, Camus M, Chaput U. Endoscopic management of complications in digestive surgery. J Visc Surg 2013; 150: 3-9.

13. Sharaiha RZ, Kim KJ, Singh VK, et al. Endoscopic stenting for benign upper gastrointestinal strictures and leaks. Surg Endosc 2014; 28: 178-84.

14. Talbot M, Yee G, Saxena P. Endoscopic modalities for upper gastrointestinal leaks, fistulae and perforations. ANZ J Surg 2015; 3: 1-6.

15. Leers JM, Vivaldi C, Schafer H, et al. Endoscopic therapy for esophageal perforation or anastomotic leak with a self-expandable metallic stent. Surg Endosc 2009; 23: 2258-62.

16. Van Heel NCM, Haringsma J, Wijnhoven BPL, Kuipers EJ. Endoscopic removal of self-expandable metal stents from the esophagus. Gastrointest Endosc 2011; 74: 44-50.

17. Fraccalvieri D, Biondo S, Saez J, et al. Management of colorectal anastomotic leakage: differences between salvage and anastomotic takedown. Am J Surg 2012; 204: 671-6.

18. Currie A, Christmas C, Aldean, Mobasheri M, Bloom TM. Systemic review of self-expanding stents in the management of benign colorectal obstruction. Colorectal Dis 2014; 16: 239-45.

19. Small AJ, Young-Fadok TM, Baron TH. Expandable metal stent placement for benign colorectal obstruction: outcomes for 23 cases. Surg Endosc 2008; 22; 454-62.

20. Lamazza A, Fiori E, Sterpetti AV, Schillaci A, Scoglio D, Lezoche E. Self-expandable metal stents in the treatment of benign anastomotic stricture after rectal resection for cancer. Colorectal Dis 2014; 16: 150-3.

21. Lamazza A, Fiori E, Sterpetti AV, Schillaci A, De Cesare A, Lezoche E. Endoscopic placement of self-expandable metallic stents for rectovaginal fistula after colorectal resection: a comparison with proximal diverting ileostomy alone. Surg Endosc 2016; 30: 797-801.

22. Lamazza A, Fiori E, Schillaci A, Sterpetti AV, Lezoche E. Treatment of anastomotic stenosis and leakage after colorectal resection for cancer with self-expandable metal stents. Am J Surg 2014; 208: 465-9. 
23. Chi P, Wang X, Lin H, Lu X, Huang Y. Endoscopic covered self-expandable metal stents implantation in the management of anastomotic leakage after colorectal cancer surgery. Zhonghua Wei Chang Wai Ke Za Zhi 2015; 18: 661-6.

24. Langer FB, Schoppmann SF, Prager G, Riegler FM, Zacherl J. Solving the problem of difficult stent removal due to tissue ingrowth in partially uncovered esophageal self-expanding metal stents. Ann Thorac Surg 2010; 89: 1691-2.

25. Hirdes MMC, Siersema PD, Houben MHMG, Weusten BLAM, Vleggaar FP. Stent-in-stent technique for removal of embedded esophageal self-expanding metal stents. Am J Gastroenterol 2011; 106: 286-93. 